\title{
The Independent Predictive Value of Peritraumatic Dissociation for Postdisaster Intrusions, Avoidance Reactions, and PTSD Symptom Severity: A 4-Year Prospective Study
}

\author{
Peter G. van der Velden \\ Institute for Psychotrauma, Zaltbommel, The Netherlands \\ Rolf J. Kleber \\ Institute for Psychotrauma, Zaltbommel, The Netherlands and Department of Clinical \\ Psychology, Utrecht University, Utrecht, The Netherlands \\ B. Christiaanse \\ Institute for Psychotrauma, Zaltbommel, The Netherlands \\ Berthold P.R. Gersons \\ Department of Psychiatry, Academic Medical Center/De Meren, University of Amsterdam, \\ Amsterdam, The Netherlands \\ Frans G.H. Marcelissen and Annelieke N. Drogendijk \\ Institute for Psychotrauma, Zaltbommel, The Netherlands \\ Linda Grievink \\ Centre for Environmental Health Research, National Institute for Public Health and the \\ Environment (RIVM), Bilthoven, The Netherlands \\ Miranda Olff and Mariel L. Meewisse \\ Department of Psychiatry, Academic Medical Center/De Meren, University of Amsterdam, \\ Amsterdam, The Netherlands
}

\begin{abstract}
This 4-year prospective study $(N=662)$ of victims of a fireworks disaster examines the independent predictive value of peritraumatic dissociation for self-reported intrusions, avoidance reactions, and posttraumatic stress disorder (PTSD) symptom severity at both 18-months (T2) and almost 4-years postdisaster (T3). Peritraumatic dissociation was measured 2-3 weeks after the disaster (T1). Hierarchical multiple regression analyses revealed that peritraumatic dissociation was not a strong independent predictor for intrusions and avoidance reactions and PTSD symptom severity at T2 or at $T 3$ above initial intrusions, avoidance reactions, and psychological distress (T1). Results suggest that an early screening procedure for peritraumatic dissociation, which is aimed at identifying disaster victims who are at risk for long-term psychological disturbances can be omitted.
\end{abstract}

\footnotetext{
B. Christiaanse is now at GGD Nieuwe Waterweg Noord, Rotterdam, The Netherlands.

The Enschede Fireworks Disaster Health Study was conducted on behalf of the Dutch Ministry of Health, Welfare and Sports. We thank Sasja Dorresteijn for her contribution to the second and third survey. We thank Rebecca Stellato of the Dutch National Institute for Public Health and the Environment (RIVM) for her contribution to the three surveys. We are grateful for the cooperation of the affected residents who participated in the surveys.

Correspondence concerning this article should be addressed to: Peter G. van der Velden, Institute for Psychotrauma, Van Heemstraweg West 5, Zaltbommel, The Netherlands. E-mail: peter.vdvelden@ivp.nl.

(C) 2006 International Society for Traumatic Stress Studies. Published online in Wiley InterScience (www.interscience.wiley.com) DOI: 10.1002/jts.20140
} 
In the aftermath of disasters, victims suffer from symptoms such as anxiety, depression, fatigue, intrusions, and avoidance reactions in the short, intermediate, or long term. A considerable minority of the victims will develop posttraumatic stress disorder (PTSD) or other mental disorders (Galea, Nandi, \& Vlahov, 2005; Norris et. al., 2002; Rubonis \& Bickman, 1991). Early detection of disaster victims who are at risk to develop such problems would help in planning for adequate care of those in need at a later date (Koopman, Classen, \& Spiegel, 1994).

In general, the probability of seeking treatment is strongly related to the severity of the psychological disorder (Bijl et al., 2003). With respect to the relation between PTSD and health services utilization, Elhai, North, and Frueh (2005) demonstrated that most studies found that PTSD diagnoses were related to increased mental health services (MHS) utilization. However, increased MHS utilization does not necessarily mean that all victims seek immediate treatment or sought treatment within a few months after the disaster. Boscarino, Adams, Stuber, and Galea (2005), for example, reported that in the first 12 months after the $9 / 11$ terrorist attacks, $55 \%$ of New Yorkers with PTSD or depression had not used MHS. Early detection may enhance activities aimed at stimulating disaster victims with these health problems to use mental health services.

After disasters, which factors predict psychological disturbances such as PTSD and identify disaster victims at risk? In recent decades, peritraumatic dissociation during or immediately after a traumatic event has been considered to be a particularly important risk factor for the development of posttraumatic stress symptoms and PTSD. The concept of peritraumatic dissociation refers to experiencing changes or distortions in the perception of time, space, and the self, during or immediately after a traumatic event (Martin \& Marchand, 2003; Nijenhuis, Van Engen, Kusters, \& Van der Hart, 2001; van der Kolk \& Van der Hart, 1989).

Ozer, Best, Lipsey, and Weiss (2003) performed a metaanalysis of 68 selected studies about predictors for posttraumatic stress symptoms following a variety of traumatic experiences. They concluded that, out of seven different factors, peritraumatic dissociation was the strongest predictor for the development of posttraumatic stress symptoms. Other predictors were prior trauma, prior psychological adjustment, a family history of psychopathology, perceived life threat during the trauma, posttrauma social support, and peritraumatic emotional responses. However, it should be noted that in the case of disasters, big differences exist in aspects such as warning time (e.g., the South Asian/tsunami disaster vs. the New Orleans/Hurricane Katrina disaster) and the number of people killed (e.g., Three-Mile Island nuclear power plant disaster vs. the 9/11 World Trade Center terrorist attacks). Such factors may influence dissociative processing.

However, the assumed predictive value of peritraumatic dissociation is not without dispute and the results of studies are ambiguous. Kindt and Engelhard (2005) noted that in Ozer et al.'s meta-analysis (2003) only $12 \%$ of the variance of PTSD symptoms was explained by peritraumatic dissociation. Martin and Marchand (2003) reported that the variance of PTSD symptoms explained by peritraumatic dissociation varies in range, and that some studies fail to demonstrate that peritraumatic dissociation independently predicts posttraumatic stress reactions (e.g., Holeva \& Tarrier, 2001, Marshall \& Schell, 2002; Simeon, Greenberg, Nelson, Schmeidler, \& Hollander, 2005).

According to Merckelbach and Muris (2001), Candel and Merckelbach (2003), Marshall and Schell (2002), and McNally (2003), several studies on this subject drew conclusions about the predictive value of peritraumatic dissociation based on retrospective investigations. The reliance on retrospective reports is questionable because of possible bias in recollections over time and the influence of current mood on memory retrieval (Harvey \& Bryant, 2000). For example, Marshall and Schell (2002) found that PTSD symptom severity and the recollection of peritraumatic dissociation was strongly correlated in two follow-up studies (3 and 12 months), but dissociation that was measured within days after the event (community violence) was not an independent predictor for PTSD symptoms suffered at 3 and 12 months afterwards. The recollection of peritraumatic dissociation proved to be unstable over time (Marshall \& Schell, 2002). 
These problems occurred in retrospective studies whether they confirmed (e.g., Marmar et al., 1999) or rejected (e.g., Gershuny, Cloitre, \& Otto, 2003) the hypothesis that peritraumatic dissociation is an independent predictor. In the longitudinal study of Marmar et al. (1999), with a follow-up at 3.5 years, peritraumatic dissociation was assessed with an average interval of 1.5 years after the event. Gershuny et al. (2003) concluded that the effect of peritraumatic dissociation on symptoms was eliminated after adjusting for event-related fear. They also acknowledged that a possible recall bias for fear and peritraumatic dissociation may have limited their conclusions as well.

Furthermore, studies differed in the way participants were asked to focus on the traumatic event and answer questions about peritraumatic dissociation. In Gershuny et al.'s (2003) study for example, participants were asked to focus on peritraumatic dissociation during the event. Jaycox, Marshall, and Orlando (2003) extended the focus to during and immediately after the event. Holeva and Tarrier (2001) asked participants to recall experiences of the traumatic event that related to peritraumatic dissociation, but did not specify a time scale.

However, Ozer et al. (2003) did not include initial psychological problems in their meta-analysis, despite the finding that these problems, such as intrusions (reexperiencing) and hyperarousal symptoms have been found to predict PTSD symptoms (Brewin, Andrews, Rose, \& Kirk, 1999; Creamer, O’Donnell, \& Pattison, 2004; Harvey \& Bryant, 2000). Birmes et al. (2003) for example, found that peritraumatic dissociation and acute stress symptoms together accounted for $33 \%$ of the explained variance in PTSD symptoms after 3 months. Their statistics showed that acute stress symptoms were marginally better independent predictors than peritraumatic dissociation.

Creamer and his colleagues (2004) found that of all acute stress disorder symptoms (ASD; American Psychiatric Association [APA], 1994), sleep difficulties, irritability, and distress were the most powerful predictors for PTSD severity at 3-months and 12-months post trauma. Dissociative symptoms did not significantly predict PTSD severity over and above the aforementioned problems. The results of Brewin et al. (1999) indicated that disso- ciative symptoms, although predictive of PTSD, did not have independent predictive value beyond the core PTSD symptoms. Simeon and her colleagues (2005) showed that peritraumatic dissociation and initial posttraumatic stress among a convenience sample of persons who felt significantly affected by the 9/11 attack, although predictive of posttraumatic stress one year after the attack, had no independent predictive value.

Therefore, it is questionable whether peritraumatic dissociation is an independent predictor for long-term psychological problems after disasters over and above initial psychological problems. To assess the predictive value of peritraumatic dissociation, we analyzed the data collected in the Enschede Fireworks Disaster Health Study. This was a prospective study of a fireworks disaster conducted over a period of almost 4 years (Grievink, Van der Velden, Yzermans, Roorda, \& Stellato, in press; Van Kamp et al., 2006; Van der Velden et al., 2005, 2006). The research question was "What is the independent predictive value of peritraumatic dissociation for intrusions and avoidance reactions, and for PTSD at both 18-months and almost 4years postdisaster, over and above intrusions and avoidance reactions and psychological distress 2-3-weeks postdisaster?”

\section{METHOD}

\section{Participants and Procedure}

On May 13, 2000, a disaster occurred in the city of Enschede (152,000 inhabitants), the Netherlands, near the Dutch border with Germany. The disaster started with exploding fireworks at 2:24 p.m. (a Saturday) in a fireworks storage and trade company. At 3:22 p.m., a fire started in one of the concrete bunkers for fireworks storage, and at 3:35 p.m., a massive explosion took place. It destroyed the central storage facilities and caused the explosion of several metal containers full of fireworks. The company was located in the middle of a residential area; approximately 500 houses were severely damaged or destroyed by fire and highly pressurized air caused by the explosion. Nineteen residents and 4 firefighters were killed and over 900 people were injured (Commissie Onderzoek Vuurwerkramp 
Enschede, 2001). In total, approximately 4,500 adult residents were affected by the disaster.

The Dutch Ministry of Health, Welfare and Sports decided to launch a comprehensive health surveillance project. This project is described in detail elsewhere (Roorda, Van Stiphout, \& Huisman-Rubingh, 2004). The Enschede Fireworks Disaster Health Study (Van Kamp et al., 2005) was part of this health surveillance project. The Medical Ethical Testing Committee (TNO-Zeist, Leiden, the Netherlands) approved our three study protocols. At Time 1 (T1), 2-3-weeks postdisaster, all affected residents were asked by mail to participate in the study. The study was also announced in the press to encourage the affected residents to participate. Data collection took place at T1 at a research center on the Twente Air Force base; the center was built specifically for the administration of the health survey. Participants were transported from Enschede to the base and were given a verbal introduction to the research project and its associated procedures. They then registered and signed informed consent forms. Blood and urine samples were collected to analyze possible fireworks-related chemical effects. Finally, questionnaires were administered in another part of the research center (van Kamp et al., 2005).

In November-December 2001 (18-months postdisaster: T2) and January-February 2004 (almost 4-years postdisaster: T3), participants who had given their written informed consent at $\mathrm{T} 1$ or $\mathrm{T} 2$ were asked to participate again. The questionnaire was sent to their home address. At T2 and $\mathrm{T} 3$, all participants received $€ 12$ euro (\$15.00 US) for their participation.

\section{Medsures}

Participants at T1, T2, and T3 completed an extensive questionnaire containing several standardized and wellvalidated instruments, measuring peritraumatic dissociation, psychological distress, intrusions, and avoidance reactions, and PTSD.

\section{Disaster experiences (e.g., damaged house and disaster} exposure). The first questionnaire (T1) included questions about the damage to the victim's homes. For the present study we made a distinction between participants who did not report severe damage $(0=$ no damage, little damage, limited damage, or severe damage that could be repaired) and participants who reported severe damage $(1=$ very severe damage that presumably could not be repaired or total destruction of their home). Disaster exposure was assessed at T1 by using a list of 21 items $(0=$ no, $1=$ yes $)$ about what participants had seen, felt, heard, or smelled during or immediately after the disaster. For example, "Had they felt air pressure from the fatal explosion"; "Had they experienced intense fear or had they seen any injured or dead people?"

Peritraumatic dissociation. The Peritraumatic Dissociative Experiences Questionnaire (PDEQ; Marmar, Weiss, \& Metzler, 1997) was administered at T1 and used to assess the extent to which dissociation had been experienced when the disaster took place or when confronted with the disaster for the first time. Each of the 10 items has a 5-point Likert scale $(1=$ not at all true, $5=$ extremely true $)$ and the total score ranges from 10 to 50 . Factor analyses (PC) showed that the Dutch version of the PDEQ represents one factor in accordance with the original PDEQ. The internal consistency was excellent (Cronbach's $\alpha=.90)$. The PDEQ has often been applied in studies examining the predictive value of peritraumatic dissociation.

Psychological distress. Psychological distress was measured at T1, T2, and T3 using the Dutch version of the Symptom Check List (SCL-90-R; Derogatis, 1977; the Dutch version is called SCL-90, Arrindell \& Ettema, 1986). Studies with the Dutch SCL-90-R, confirmed concurrent validity of all subscales except for obsessivecompulsive behavior. This means that the Dutch SCL90-R consists of eight subscales, of which five subscales were identical to the original version (Anxiety, Sleeping Problems, Somatization, Hostility, Phobic Anxiety), and one was nearly identical (Depression). The validity and reliability of the Dutch SCL-90-R has proven to be satisfactory (see Arrindell \& Ettema, 1986, 2003). Items have a 5-point Likert scale $(1=$ not at all, $5=$ extremely $)$ and assessed several symptoms over the past 7 days. For this 
research, the SCL-90-R total score was used (summation of all 90 items). At all assessment moments, the internal consistencies of the total scores were excellent, Cronbach's $\alpha \geq .95$.

Intrusions and avoidance reactions. To assess disasterrelated intrusions and avoidance reactions the Dutch version of the Impact of Event Scale was applied at T1, T2, and T3 (IES; Brom, Kleber, \& Defares, 1986; Horowitz, Wilner, \& Alvarez, 1979). Scores on the 15 items were rated on a 4 -point Likert scale $(0=$ not at all, $5=$ often $)$ and assessed the degree of disaster-related intrusions and avoidance reactions over the past 7 days, with total scores ranging from 0 to 75 . The reliability and structure of the Dutch IES has proven to be adequate across various traumatic stressors. It has a robust structure, supporting the composition (Intrusions and Avoidance scale) of the original IES (see Van der Ploeg, Mooren, Kleber, Van der Velden, \& Brom, 2004). At all measurement points, the internal consistency was excellent, Cronbach's $\alpha \geq .94)$.

Posttraumatic stress syndrome. The Posttraumatic Stress Disorder Self-Rating Scale (SRS-PTSD; Carlier, Lamberts, Van Uchelen, \& Gersons, 1998) was applied to assess disaster-related PTSD based on the criteria defined in the Diagnostic and Statistical Manual of Mental Disorders, Fourth Edition (DSM-IV; American Psychiatric Association, 1994) during the last 4 weeks at T2 and T3. The SRS-PTSD was not applied at T1 because PTSD can, by definition, only be diagnosed after one month. Issues related to intrusions (five items), avoidance reactions (seven items), and hyperarousal symptoms (five items) were rated on several 3-point Likert scales (for example, $1=$ not at all, $3=4$ times or more per week; $1=$ not at all, $3=$ extremely). A person had PTSD if he or she met the criteria of intrusions (at least one out of five items), avoidance reactions (at least three out of seven items), and hyperarousal symptoms (at least two out of five items). For the present study, a PTSD symptom severity score was calculated by adding together the items' sums of intrusions $(1=0,2=$ at least $1)$, avoidance reactions $(1=0,1,2 ; 2=$ at least 3$)$, and of hyperarousal symptoms $(1=0$ or $1,2=$ at least 2$)$. Internal consistencies of the SRS-PTSD at T2 and T3 were excellent (Cronbach's $\alpha \geq .89$ ). In a recent review of screening instruments for adults at risk for PTSD, Brewin (2005) concluded that the SRS-PTSD demonstrated a good balance between sensitivity and specificity, with high levels of both.

For all translated measures (PDEQ, SCL-90-R, IES) a back translation procedure was used (the original English version was translated into Dutch, and the Dutch version was translated back into English to ensure a precise translation).

\section{Results}

\section{Participants}

The present report is based on a selected cohort of 662 affected residents of Dutch origin who participated in all three surveys. At T1, 1,083 residents participated. Of the adult victims, approximately $74 \%$ were Dutch natives (estimated response Dutch natives at $\mathrm{T} 1=32.8 \%$ ). At $\mathrm{T} 2$, out of 1,071 residents who could be asked to participate again (12 migrated, died, or their address was unknown), 861 participated $(80.4 \%)$. At T3, out of 995 residents who could participate, 757 did so (76.1\%). Residents who participated at $\mathrm{T} 1$ and gave their written consent but did not participate at T2 were asked to participate again at T3.

Nonresponse analyses revealed that the group of nonresponders $(n=128)$ at T2 and T3 consisted of significantly more men than women $(59.8 \%$ vs. $42.7 \%)$, and had a significantly lower education level (2.5 vs. 2.7$)$ than responders at T2 and T3 $(n=662)$. Furthermore, they reported significantly more psychological distress at $\mathrm{T} 1$ (51.8\% vs. $37.1 \%)$. However, there were no significant differences between responders and nonresponders in age, PDEQ scores, intrusions, and avoidance reactions at T1 (IES), mean scores on the disaster exposure list, and percentage of affected residents with severely damaged or destroyed homes. We could not compare PTSD symptom severity because the SRS-PTSD was not administered at T1 (see above). 


\section{Descriptive Statistics and Correlation Analuses}

Of the participants, $75.6 \%$ had seen the explosion, $74 \%$ had felt the pressurized air from the explosion, and $60.4 \%$ reported intense fear. There were $65.1 \%$ of the study participants who had seen injured victims and 21.6\% reported seeing severely injured victims, $8.3 \%$ had seen dead people, $37.8 \%$ had experienced palpitations, and $43.5 \%$ had heard the screaming of children during or immediately after the disaster.

At T1-2-3-weeks postdisaster-PTSD could not be assessed. Dependent on the IES cut-off score ( $>25,35$, or $45), 70.6 \%, 49 \%$, and $28.1 \%$ of the participants reported strong intrusions and avoidance reactions $2-3$-weeks postdisaster. Compared to other disaster studies (e.g., Galea et al., 2005) that used the IES, a relatively high proportion of victims in our sample reported high levels of intrusions and avoidance reactions. Approximately $37 \%$ reported high or very high levels of psychological distress at T1, which is about twice as much as a normal population of 18 years and older (Arrindell \& Ettema, 1986, 2003). According the SRS-PTSD, the proportion of victims who met the criteria for PTSD was not high at 18-months (13.4\%) or almost 4years postdisaster (9.7\%; e.g., Galea et al., 2005). Catapano et al. (2005), for example, found that $27.6 \%$ of the victims of a landslide met the criteria of PTSD according the SRS-PTSD one year after the disaster. However, immigrants were excluded in the present study, which may partly explain these results. An earlier study (Drogendijk et al., 2003) showed that at T2 a much higher proportion of affected (Turkish) immigrants scored high or very high on all SCL-90-R subscales when compared with a control group of (Turkish) immigrants (ORs varied between 3.1 and 8.7). There were smaller significant differences in health problems between affected Dutch natives and a control group of Dutch origin (ORs varied between 1.7 and 3.2).

Table 1 shows the means, the standard deviations of variables selected for the regression analyses, and the number of subjects who completed the questionnaires. Correlation analyses showed significant relationships between several demographic characteristics, disaster experiences, psychological problems, and peritraumatic dissociation.
Peritraumatic dissociation, initial psychological distress, intrusions, and avoidance reactions were significantly correlated with PTSD symptom severity, intrusions, and avoidance reactions measured at $\mathrm{T} 2$ and $\mathrm{T} 3$ $(.31<r<.53)$.

\section{Multiple Regression Analuses}

To determine the independently predictive value of peritraumatic dissociation, hierarchical multiple regression analyses were conducted (SPSS version 12.0). Intrusions, avoidance reactions, and PTSD symptom severity at T2 and T3 were the dependent variables. At Step 1, gender, age, education level, extent of house damage, and the level of disaster exposure were entered as control variables. At Step 2, intrusions, avoidance reactions, and psychological distress at T1 were entered. Finally, peritraumatic dissociation was added to the model (Step 3). The results are shown in Tables 2 and 3.

\section{Prediction of Intrusions and Avoidance Reactions}

Intrusions, avoidance reactions, and psychological distress 2-3-weeks postdisaster independently predicted intrusions and avoidance reactions at T2 and T3: T2 Step 1,F(4, $576)=20.6, p<.001 ;$ T2 Step $2, F(2,574)=98.9$, $p<.001$; T3 Step $1, F(4,576)=28.1, p<.001$; T3 Step 2, $F(2,574)=70.3, p<.001$. At Step 2, 22\% and 16\%, respectively, of the variance of intrusions and avoidance reactions at $\mathrm{T} 2$ and $\mathrm{T} 3$ were explained by initial reactions and distress. Initial distress and intrusions and avoidance reactions were the strongest predictors for intrusions and avoidance reactions at $\mathrm{T} 2, \beta=.35$ and .22 , respectively, and at $\mathrm{T} 3, \beta=.27$ and .22 , respectively. When peritraumatic dissociation was entered at Step 3, a significant though very small proportion of explained variance $(0.8 \%)$ was added to the explained variance of intrusions and avoidance reactions, T2 Step $3 F(1,574)=7.6, p<.05$. However, the beta was negative, $\beta=-.13$. The PDEQ did not independently predict intrusions and avoidance reactions at T3 Step 3, $F(1,573)<1$, ns. 


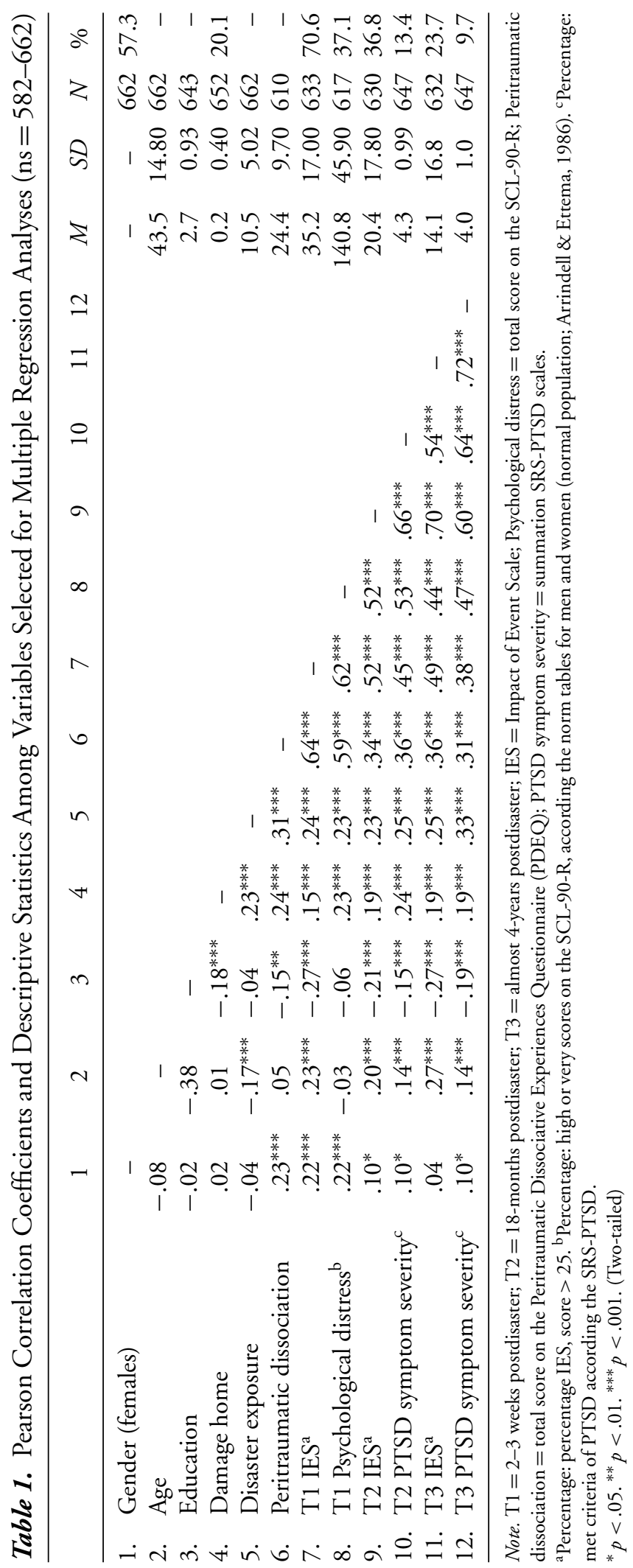


In total, $37 \%$ and $36 \%$ of the variance of intrusions and avoidance reactions for T2 and T3, respectively, was explained by demographic characteristics, disaster experiences, initial intrusions, and avoidance reactions, and psychological distress (see Table 2).

\section{Prediction of PTSD Sumptom Severitu}

Initial intrusions and avoidance reactions and psychological distress independently predicted PTSD symptom severity at T2, Step $1 F(4,576)=19.7, p<.001$; Step $2 F(2$, $574)=87.9, p<.001$. Twenty percent of the variance of PTSD symptom severity at T2 was explained by initial distress and reactions. In contrast to intrusions and avoidance reactions at T2, initial psychological distress was a much stronger independent predictor for PTSD symptom severity at $\mathrm{T} 2, \beta=.40$, than initial intrusions and avoidance reactions were, $\beta=.12$. Results revealed that peritraumatic dissociation was not an independent predictor for PTSD symptom severity at $\mathrm{T} 2$, Step $3 F(1,573)=1.7$, ns.

For PTSD symptom severity at T3, a somewhat different pattern emerged. Of the initial psychological reactions after the disaster, only psychological distress, $\beta=.36$, had a significantly independent predictive value, Step $1 F(4$, $576)=16.4, p<.001$; Step $2 F(2,574)=59.2, p<.001$. Peritraumatic dissociation did not have a significantly independent predictive value, Step $3 F(1,573)=1.2$, ns.

Table 2. Hierarchical Multiple Regression Analyses of Factors Related to Intrusions and Avoidance Reactions 18 Months and Almost 4 Years Postdisaster

\begin{tabular}{|c|c|c|c|c|c|c|c|c|}
\hline & \multicolumn{4}{|c|}{ 18-months postdisaster } & \multicolumn{4}{|c|}{ 4-years postdisaster } \\
\hline & $\Delta R^{2}$ & $B$ & $S E B$ & $\beta$ & $\Delta R^{2}$ & $B$ & $S E B$ & $\beta$ \\
\hline \multicolumn{9}{|c|}{ Step 1: Demographic characteristics and disaster experiences } \\
\hline Gender (female) & $.15^{* * *}$ & 4.32 & 1.38 & $.12^{* *}$ & $.20^{* * *}$ & 2.15 & 1.27 & .06 \\
\hline Age & & 0.26 & 0.05 & $.22^{* * *}$ & & 0.31 & 0.05 & $.27^{* * *}$ \\
\hline Education level & & -1.75 & 0.83 & $-.09^{*}$ & & -2.32 & 0.75 & $-.13^{* *}$ \\
\hline Damage home & & 5.30 & 1.78 & $.12^{* *}$ & & 4.51 & 1.63 & $.11^{* *}$ \\
\hline Disaster exposure & & 0.84 & 0.14 & $.24^{* * *}$ & & 0.90 & 0.13 & $.27^{* * *}$ \\
\hline \multicolumn{9}{|c|}{ Step 2: Initial posttraumatic stress symptoms and psychological distress } \\
\hline Gender (female) & $.22^{* * *}$ & -0.42 & $1.25^{\circ}$ & -.01 & $.16^{* * *}$ & -1.71 & 1.19 & -.05 \\
\hline Age & & 0.19 & 0.05 & $.16^{* * *}$ & & 0.24 & 0.04 & $.21^{* * *}$ \\
\hline Education level & & -1.04 & 0.72 & -.05 & & -1.67 & 0.69 & $-.09^{*}$ \\
\hline Damage home & & 2.04 & 1.56 & .05 & & 2.00 & 1.49 & .05 \\
\hline Disaster exposure & & 0.37 & 0.13 & $.10^{* *}$ & & 0.51 & 0.12 & $.15^{* * *}$ \\
\hline T1 IES & & 0.24 & 0.05 & $.22^{* * *}$ & & 0.22 & 0.05 & $.22^{* * *}$ \\
\hline T1 SCL-90-R & & 0.13 & 0.02 & $.35^{* * *}$ & & 0.10 & 0.02 & $.27^{* * *}$ \\
\hline \multicolumn{9}{|c|}{ Step 3: Peritraumatic dissociation } \\
\hline Gender (female) & $.008^{*}$ & -0.03 & 1.25 & -.00 & .00 & -1.65 & 1.20 & -.05 \\
\hline Age & & 0.19 & 0.05 & $.16^{* * *}$ & & 0.24 & 0.04 & $.21^{* * *}$ \\
\hline Education level & & -1.04 & 0.71 & -.05 & & -1.68 & 0.69 & $-.09^{*}$ \\
\hline Damage home & & 2.54 & 1.57 & .06 & & 2.08 & 1.50 & .05 \\
\hline Disaster exposure & & 0.43 & 0.13 & $.12^{* *}$ & & 0.52 & 0.12 & $.16^{* * *}$ \\
\hline T1 IES & & 0.29 & 0.05 & $.28^{* * *}$ & & 0.22 & 0.05 & $.23^{* * *}$ \\
\hline T1 SCL-90-R & & 0.15 & 0.02 & $.38^{* * *}$ & & 0.10 & 0.02 & $.28^{* * *}$ \\
\hline PDEQ & & -0.24 & 0.09 & $-.13^{* *}$ & & -0.04 & 0.08 & -.02 \\
\hline
\end{tabular}

Note. T1 = 2-3 weeks postdisaster. IES = Impact of Event Scale; SCL-90-R= Psychological distress, total score on the SCL-90-R; PDEQ= Peritraumatic Dissociative Experiences Questionnaire (PDEQ); SRS-PTSD = Self Rating Scale for Posttraumatic Stress Disorders.

${ }^{*} p<.05 .{ }^{* *} p<.01 .{ }^{* * *} p<.001$. 
Demographic characteristics, disaster experiences, initial distress, and intrusions and avoidance reactions accounted for $35 \%$ and $28 \%$ of the variance of PTSD symptom severity at $\mathrm{T} 2$ and $\mathrm{T} 3$, respectively (see Table 3 ).

The correlations between the IES and the SCL-90-R at $\mathrm{T} 1$, and peritraumatic dissociation were high, .64 and .59, respectively. For this reason the hierarchical multiple regression analyses were repeated with only the IES and then with only the SCL-90-R as a measure for initial psychological problems at Step 2. Results showed that peritraumatic dissociation did not emerge as a significantly independent predictor for intrusions and avoidance reactions or PTSD at T2 and T3 (data not shown).

\section{DISCUSSION}

This prospective disaster study started 2-3-weeks postdisaster and continued over a period of almost 4 years. To our knowledge, this is the first prospective disaster study where the predictive value of peritraumatic dissociation for long-term intrusions and avoidance reactions and PTSD symptom severity was analyzed over and above intrusions and avoidance reactions and psychological distress 2-3weeks postdisaster.

We assume that the closer the measurement of peritraumatic dissociation to the actual day of the disaster, the more accurate the measurement will be. In our study

Table 3. Hierarchical Multiple Regression Analyses of Factors Related to Posttraumatic Stress Disorder (PTSD) Symptom Severity 18 Months and Almost 4 Years Postdisaster

\begin{tabular}{|c|c|c|c|c|c|c|c|c|}
\hline & \multicolumn{4}{|c|}{ 18-months postdisaster } & \multicolumn{4}{|c|}{ 4-years postdisaster } \\
\hline & $\Delta R^{2}$ & $B$ & $S E B$ & $\beta$ & $\Delta R^{2}$ & $B$ & $S E B$ & $\beta$ \\
\hline \multicolumn{9}{|c|}{ Step 1: Demographic characteristics and disaster experiences } \\
\hline Gender (female) & $.15^{* * *}$ & 0.23 & 0.08 & $.12^{* *}$ & $.13^{* * *}$ & 0.23 & 0.08 & $.11^{* *}$ \\
\hline Age & & 0.01 & 0.00 & $.18^{* *}$ & & 0.01 & 0.00 & $.15^{\text {** }}$ \\
\hline Education level & & -0.04 & 0.05 & -.04 & & -0.10 & 0.05 & $-.09^{*}$ \\
\hline Damage home & & 0.44 & 0.10 & $.18^{* * *}$ & & 0.32 & 0.10 & $.13^{* *}$ \\
\hline Disaster exposure & & 0.05 & 0.01 & $.25^{* * *}$ & & 0.05 & 0.01 & $.23^{* * *}$ \\
\hline \multicolumn{9}{|c|}{ Step 2: Initial posttraumatic stress symptoms and psychological distress } \\
\hline Gender (female) & $.20^{* * *}$ & -0.01 & 0.07 & -.00 & $.15^{* * *}$ & 0.03 & 0.08 & .01 \\
\hline Age & & 0.01 & 0.00 & $.15^{* * *}$ & & 0.01 & 0.00 & $.13^{* *}$ \\
\hline Education level & & -0.01 & 0.04 & -.01 & & -0.09 & 0.04 & $-.08^{*}$ \\
\hline Damage home & & 0.25 & 0.09 & $.10^{* *}$ & & 0.14 & 0.09 & .06 \\
\hline Disaster exposure & & 0.03 & 0.01 & $.13^{* *}$ & & 0.03 & 0.01 & $.13^{*}$ \\
\hline T1 IES & & 0.01 & 0.00 & $.12^{*}$ & & 0.00 & 0.00 & .05 \\
\hline T1 SCL-90-R & & 0.01 & 0.00 & $.40^{* * *}$ & & 0.01 & 0.00 & $.39^{* * *}$ \\
\hline \multicolumn{9}{|c|}{ Step 3: Peritraumatic dissociation } \\
\hline Gender (female) & .00 & 0.00 & 0.07 & .00 & .00 & 0.04 & 0.07 & .02 \\
\hline Age & & 0.01 & 0.00 & $.14^{* * *}$ & & 0.01 & 0.00 & $.13^{* *}$ \\
\hline Education level & & -0.01 & 0.04 & -.01 & & -0.09 & 0.04 & $-.08^{*}$ \\
\hline Damage home & & 0.26 & 0.09 & $.11^{* *}$ & & 0.15 & 0.10 & .06 \\
\hline Disaster exposure & & 0.03 & 0.01 & $.13^{* * *}$ & & 0.03 & 0.01 & $.14^{* *}$ \\
\hline T1 IES & & 0.01 & 0.00 & $.15^{* *}$ & & 0.00 & 0.00 & .07 \\
\hline T1 SCL-90-R & & 0.01 & 0.00 & $.42^{* * *}$ & & 0.01 & 0.00 & $.40^{* * *}$ \\
\hline PDEQ & & 0.00 & 0.00 & -.03 & & -0.01 & 0.01 & -.06 \\
\hline
\end{tabular}

Note. $\mathrm{T} 1=2-3$ weeks postdisaster. IES $=$ Impact of Event Scale; SCL-90-R = Psychological distress, total score on the SCL-90-R; PDEQ = Peritraumatic Dissociative Experiences Questionnaire (PDEQ); SRS-PTSD = Self Rating Scale for Posttraumatic Stress Disorder. ${ }^{*} p<.05 .{ }^{* *} p<.01 .{ }^{* * *} p<.001$. 
peritraumatic dissociation was assessed after a relatively short period following the event (2-3 weeks postdisaster; e.g., Holeva \& Tarrier, 2001). We were unable to assess peritraumatic dissociation among affected residents within a few days of the disaster, as in the study of Marshall and Schell (2002) among victims of community violence. This had to do with external factors: It took some time before permission was granted from authorities to conduct the study and to organize the survey. However, we expect that the relatively short lapse of time reduced the problem of rapid forgetfulness or possible memory distortions.

We did not find disaster-related peritraumatic dissociation to be a powerful independent predictor for intrusions, avoidance reactions, or for PTSD symptom severity 18-months and four-years postdisaster, when initial psychological distress as measured with the SCL-90-R and/or intrusions and avoidance reactions as measured with the IES were taken into account.

Although peritraumatic dissociation was a significant predictor for intrusions and avoidance reactions 18months postdisaster (when both initial distress and reactions were entered into the model), the proportion of the explained variance was miniscule $(0.8 \%)$. The beta for peritraumatic dissociation was negative, while the zero-order correlation was positive, indicating that peritraumatic dissociation did act as a suppressor variable in this analysis. Given the minor added proportion of explained variance in this analysis and the absence of significant effects in the analysis with only one variable of initial psychological problems (IES or SCL-90-R), we conclude that in this sample peritraumatic dissociation did not serve as a protector for later psychological disturbances.

Correlation analyses revealed significant associations between peritraumatic dissociation and later psychological problems. These findings are consistent with earlier research. Therefore, our results do not contradict the suggestion of Ozer et al. (2003) that peritraumatic dissociation is a predictor. However, we did not find peritraumatic dissociation to be a strong independent predictor (e.g., Brewin et al., 1999; Marshall \& Schell, 2002; Simeon et al., 2005).
This study shows that initial intrusions, avoidance reactions, and psychological distress are independent predictors for intrusions, avoidance reactions, and for PTSD symptom severity. However, in contrast to initial psychological distress, intrusions and avoidance reactions were not independent predictors for PTSD symptom severity 4 years after the disaster. In a prospective study, Bromet, Havenaar, Glutzman, and Tintle (2005) found that predisaster lifetime mental health-substance disorder predicted PTSD 6 months after the disaster. We found that the beta of initial distress at Step 2 for PTSD symptom severity at T2, .40 , was much higher than the beta of initial intrusions and avoidance reactions, .12 . These results may indicate that initial psychological distress partly measures preexisting psychopathology, more so than initial intrusions and avoidance reactions do.

The finding that severe damage or destruction of the home and subsequent forced relocation is a risk factor for intrusions and avoidance reactions at 4-years postdisaster and PTSD symptom severity, both at 18-months and 4-years postdisaster is consistent with the research of Bland et al. (1997). However, it does not comply with findings of Riad and Norris (1996).

To identify disaster victims who are most likely to develop long-term psychological disturbances, it is valid to screen for material damage, disaster exposure, initial intrusions, avoidance reactions, and psychological distress. We conclude that in such a procedure, screening for peritraumatic dissociation can be omitted (e.g., Marshall \& Schell, 2002; Simeon et al., 2005). However, the SCL-90$\mathrm{R}$ is a relatively large and time-consuming questionnaire (90 items) compared to the IES (15 items) and the PDEQ (10 items). A relatively brief and valid instrument measuring psychological distress can solve this problem.

We did not investigate the predictive value of peritraumatic dissociation for psychological disturbances a few months postdisaster. Peritraumatic dissociation can be an independent predictor for disaster-related PTSD symptom severity a few months after a disaster (e.g., Birmes et al., 2003, Koopman et al., 1994; Shalev, Peri, Canetti, \& Schreiber, 1996). Correlations in our study between peritraumatic dissociation and psychological problems 
2-3-weeks postdisaster are significant and strong: Pearson's correlation with the SCL-90-R was .59 and with the IES was .64. However, in light of the results of Marshall and Schell (2002), a causal interpretation of these correlations should not be made.

This study has some limitations. First, participants were Dutch natives aged 18 years and older. Therefore, no conclusions can be drawn about the predictive value of peritraumatic dissociation among ethnic minorities and children. The estimated response at $\mathrm{T} 1$ was relatively low (33\%), but low response percentages are not unusual in studies where blood samples are also taken (e.g., Van den Viet et al., 2002). Furthermore, men, participants with a relatively low level of education, and participants with psychological distress showed a greater dropout rate. Therefore, participants in our study cannot be considered as representative of the disaster-affected residents.

However, it is unclear to what extent the loss of these participants biased our conclusions. Nonresponse analyses showed that nonresponders had the same level of peritraumatic dissociation, intrusions, and avoidance reactions. The same percentage of nonresponders as participants had severe damage and destruction to their homes and the same mean scores on the disaster exposure list.

Furthermore, it is unclear whether our results can be generalized to types of trauma from other than man-made disasters (see, for instance, the results on childbirth stress by Olde et al., 2005). Potential risk factors such as peritraumatic dissociation may not be equivalent across different types of trauma (Brewin, Andrews, \& Valentine, 2000). Disasters, unlike sexual abuse, violence, and war, happen unintentionally and the traumatic experiences are limited in time (Type I Trauma; Terr, 1991). Intentional events generally lead to poorer levels of health than nonintentional events (e.g., Kessler, Sonnega, Hughes, \& Nelson, 1995). This may influence the level of peritraumatic dissociation and the relationship between peritraumatic dissociation and psychological problems. Nevertheless, Marshall and Schell's (2003) key finding in their prospective study of men (primarily) who were victims of community vio- lence was that peritraumatic dissociation did not emerge as an independent predictor.

We used self-rating measures for mental health problems and PTSD. Both the IES and the SCL-90-R are well-validated instruments. We did not use the IES-R because at the start of our study (May 2000) a well-validated Dutch IES-R was not yet available. In our study, no clinical diagnoses were made: Clinical assessments may have led to other results with respect to PTSD symptom severity. This study did not include other variables that predicted postdisaster mental health problems (see Brewin et al., 2000; Ozer et al., 2003), such as predisaster depression, prior trauma, and lack of social support (e.g. Ginexi, Weihs, Simmens, \& Hoyt, 2000; Galea et al., 2005; Simeon et al., 2005).

\section{CONCLUSION}

Despite these limitations, our study provides new and interesting data about the predictive value of peritraumatic dissociation for long-term psychological disturbances after a disaster. The advantage of our study (e.g., Gershuny et al., 2003) is that we assessed the predictive value of peritraumatic dissociation within the context of a 4-year longitudinal prospective study.

\section{REFERENCES}

American Psychiatric Association. (1994). Diagnostic and statistical manual of mental disorders (4th ed.). Washington DC: Author.

Arrindell, W. A., \& Ettema, J. H. M. (1986, 2003). Handleiding bij een multidimensionele psychopathologie-indicator SCL90 [Manual for a multidimensional psychopathology indicator SCL-90]. Lisse, the Netherlands: Swets \& Zeitlinger/Swets Test Publishers.

Bijl, R. V., De Graaf, R., Hiripi, E., Kessler, R. C., Kohn, R., Offord, D. R., et al. (2003). The prevalence of treated and untreated mental disorders in five countries. Health Affairs, 22, 122133.

Birmes, P., Brunet, A., Carreras, D., Ducasse, J., Charlet, J., Lauque, D., et al. (2003). The predictive power of peritraumatic 
dissociation and acute stress symptoms for posttraumatic stress symptoms: A three-month prospective study. American Journal of Psychiatry, 160, 1337-1339.

Bland, S. H., O'Leary, E. S., Farinaro, E., Jossa, F., Krogh, V., Violanti, J. M., et al. (1997). Social network disturbances and psychological distress following earthquake evacuation. Journal of Nervous and Mental Disease, 185, 88-195.

Boscarino, J. A., Adams, R. E., Stuber, J., \& Galea, S. (2005). Disparities in mental health treatment following the World Trade Center disaster: Implications for mental health care and mental health services research. Journal of Traumatic Stress, 18, 287297.

Brewin, C. R. (2005). Systematic review of screening instruments for adults at risk for PTSD. Journal of Traumatic Stress, 18, 53-62.

Brewin, C. R., Andrews, B., Rose, S., \& Kirk, M. (1999). Acute stress disorder and posttraumatic stress disorder in victims of violent crime. American Journal of Psychiatry, 156, 360-366.

Brewin, C. R., Andrews, A., \& Valentine, J. D. (2000). Meta-analysis or risk factors for posttraumatic stress disorder in trauma-exposed adults. Journal of Clinical and Consulting Psychology, 68, 748766.

Brom, D., Kleber, R. J., \& Defares, P. B. (1986). Traumatische ervaringen en psychotherapie [Traumatic experiences and psychotherapy]. Amsterdam/Lisse, the Netherlands: Swets \& Zeitlinger.

Bromet, E. J., Havenaar, J. M., Glutzman, S. F., \& Tintle, N. L. (2005). Psychological aftermath of the Lviv air show disaster: A prospective controlled study. Acta Psychiatrica Scandinavica, 112,194-200.

Candel, I., \& Merckelbach, H. (2003). Peritraumatische dissociatie als voorspeller van posttraumatische stressstoornis: Een kritische noot [Peritraumatic dissociation as a predictor of posttraumatic stress disorder: A critical note]. Tijdschrift voor Psychiatrie, 45, 211-219.

Carlier, I. V. E., Lamberts, R. D., Van Uchelen, A. J., \& Gersons, B. P. R. (1998). Clinical utility of a brief diagnostic test for posttraumatic stress disorder. Psychosomatic Medicine, 60, 4247.

Catapano, F., Malafronte, R., Lepre, F., Cozzolino, P., Arnone, R., Lorenzo, E., et al. (2005). Psychological consequences of the 1998 landslide in Sarno, Italy: A community study. Acta Psychiatrica Scandinavica, 104, 438-442.

Creamer, M., O’Donnell, M. L., \& Pattison, P. (2004). The relationship between acute stress disorder and posttraumatic stress disorder in severely injured trauma survivors. Behaviour Research and Therapy, 42, 315-328.
Commissie Onderzoek Vuurwerkramp Enschede. (2001). Deel A. De vuurwerkramp: SE Fireworks, de overheid, de ramp [Part A. The fireworks disaster: SE Fireworks, the government, the disaster]. Enschede/Den Haag, the Netherlands: Author.

Derogatis, L. R. (1977). SCL-90-R: Administration, scoring and procedures manual-I for the revised version. Baltimore: Johns Hopkins University School of Medicine, Clinical Psychometrics Research Unit.

Drogendijk, A. N., Van der Velden, P. G., Kleber, R. J., Christiaanse, B. B. A., Dorresteijn, S. M., Grievink, L., et al. (2003). Turkse getroffenen vuurwerkramp Enschede: Een vergelijkende studie [Turkish victims of the fireworks disaster Enschede: A comparative study]. Gedrag \& Gezondheid, 31, 145-162.

Elhai, J. D., North, T. C., \& Frueh, B. C. (2005). Health service use predictors among trauma survivors: A critical review. Psychological Services, 2, 3-19.

Galea, S., Nandi, A., \& Vlahov, D. (2005). The epidemiology of posttraumatic stress disorder after disasters. Epidemiologic Reviews, 27, 78-91.

Gershuny, B. S., Cloitre, M., \& Otto, M. W. (2003). Peritraumatic dissociation and PTSD severity: Do event-related fears about death and control mediate their relation. Behaviour Research and Therapy, 41, 157-166.

Ginexi, E. M., Weihs, K., Simmens, S. J., \& Hoyt, D. R (2000). Natural disaster and depression: A prospective investigation of reactions to the 1993 Midwest floods. American Journal of Community Psychology, 28, 495-518.

Grievink, L., Van der Velden, P. G., Yzermans, C. J., Roorda, J., \& Stellato, R. K. (in press). The importance of estimating selection bias on prevalence estimates shortly after a disaster. Annals of Epidemiology.

Harvey, A. G., \& Bryant, R. A. (2000). Two-years prospective evaluation of the relationship between acute stress disorder and posttraumatic stress disorder following mild brain injury. American Journal of Psychiatry, 157, 626-628.

Holeva, V., \& Tarrier, N. (2001). Personality and peritraumatic dissociation in the prediction of severity in victims of road traffic accidents. Journal of Psychosomatic Research, 51, 687692.

Horowitz, M., Wilner, M., \& Alvarez, W. (1979). Impact of event scale: A measure of subjective stress. Psychosomatic Medicine, 41, 209-218.

Jaycox, L. H., Marshall, G. N., \& Orlando, M. (2003). Predictors of acute distress among young adults injured by community violence. Journal of Traumatic Stress, 16, 237-245. 
Kessler, R. C., Sonnega, A., Hughes, M., \& Nelson, C. B. (1995). Posttraumatic stress disorder in the national comorbidity survey. Archives of General Psychiatry, 52, 1048-1060.

Kindt, M., \& Engelhard, I. M. (2005). Trauma processing and the development of posttraumatic stress disorder. Journal of Behavior Therapy and Experimental Psychiatry, 36, 6976.

Koopman, C., Classen, C., \& Spiegel, M. D. (1994). Predictors of posttraumatic stress symptoms among survivors of the Oakland/Berkeley, Calif., firestorm. American Journal of Psychiatry, 151, 888-894.

Marmar, C. R., Weiss, D. S., \& Metzler, T. J. (1997). The peritraumatic dissociation experiences questionnaire. In J. P. Wilson \& T. M. Keane (Eds.), Assessing psychological trauma and severity (pp. 412-428). New York: Guilford Press.

Marmar, C. R., Weiss, D. S., Metzler, T. J., Delucchi, K. L., Best, S. R., \& Wentworth, K. A. (1999). Longitudinal course and predictors of continuing distress following critical incident exposure in emergency services personnel. Journal of Nervous and Mental Disease, 187, 15-22.

Marshall, G. N., \& Schell, T. L. (2002). Reappraising the link between peritraumatic dissociation and severity symptom severity: Evidence from a longitudinal study of community violence. Journal of Abnormal Psychology, 111, 626-636.

Martin, A., \& Marchand, A. (2003). Prediction of posttraumatic stress disorder: Peritraumatic dissociation, negative emotions and physical anxiety among French speaking university students. Journal of Trauma and Dissociation, 4(2), 49-63.

McNally, R. J. (2003). Progress and controversy in the study of posttraumatic stress disorder. Annual Review of Psychology, 54, 229-252.

Merckelbach, H., \& Muris, P. (2001). The causal link between selfreported trauma and dissociation: A critical review. Behaviour Research and Therapy, 39, 245-254.

Nijenhuis, E., Van Engen, A., Kusters, I., \& Van der Hart, O. (2001). Peritraumatic somatoform and psychological dissociation in relation to recall of childhood sexual abuse. Journal of Trauma and Dissociation, 2(3), 49-68.

Norris, F. H., Friedman, M., Watson, P. J., Byrne, C. M., Diaz, E., \& Kaniasty, K. (2002). 60,000 disaster victims speak: Part I. An empirical review of the empirical literature, 1981-2001. Psychiatry: Interpersonal and Biological Processes, 65, 207239.

Olde, E., Van der Hart, O., Kleber, R. J., Van Son, M. J. M., Wijnen, H. A. A., \& Pop, V. J. M. (2005). Peritraumatic disso- ciation and emotions as predictors of PTSD symptoms following childbirth. Journal of Trauma and Dissociation, 6(3), 125142.

Ozer, E. J., Best, S. R., Lipsey, T. L., \& Weiss, D. S. (2003). Predictors of posttraumatic stress disorder and symptoms in adults: A metaanalysis. Psychological Bulletin, 129, 52-73.

Riad, J. K., \& Norris, F. H. (1996). The influence of relocation on the environmental, social and psychological stress experienced by disaster victims. Environment and Behavior, 28, 163182.

Roorda, J., Van Stiphout, W. A., \& Huijsman-Rubingh, R. R. R. (2004). Post-disaster health effects: Strategies for investigation and data-collection. Experiences from the Enschede fireworks disaster. Journal of Epidemiology and Community Health, 58, 982-987.

Rubonis, A. V., \& Bickman, L. (1991). Psychological impairment in the wake of disaster: The disaster-psychopathology relationship. Psychological Bulletin, 109, 384-399.

Shalev, A. Y., Peri, T., Canetti, L., \& Schreiber, S. (1996). Predictors of severity in injured trauma survivors: A prospective study. American Journal of Psychiatry, 153, 219225.

Simeon, D., Greenberg, J., Nelson, D., Schmeidler, J., \& Hollander, E. (2005). Dissociation and posttraumatic stress 1 year after the World Trade Center disaster: Follow-up of a longitudinal survey. Journal of Clinical Psychiatry, 66, 231-237.

Terr, L. C. (1991). Childhood traumas: An outline and overview. American Journal of Psychiatry, 148, 10-20.

Van den Viet, A. L., Hof, S., Elvers, L. H., Seidell, J. C., Otten, F., \& Veldhuizen, H. (2002). Risicofactoren en gezondheidsevaluatie Nederlandse bevolking, een onderzoek op GGD'en [Risk factors and health in the Netherlands, a survey by municipal public: Annual report 2000]. Bilthoven, The Netherlands: National Institute of Public Health and Environment.

Van der Kolk, B. A., \& Van der Hart, O. (1989). Pierre Janet and the breakdown of adaptation to psychological trauma. American Journal of Psychiatry, 146, 1530-1540.

Van der Ploeg, E., Mooren, T. M., Kleber, R. J., Van der Velden, P. G., \& Brom, D. (2004). Construct validation of the Dutch version of the Impact of Event Scale. Psychological Assesment, $16,16-26$.

Van der Velden, P. G., Grievink, L., Dorresteijn, A. M., Van Kamp, I., Drogendijk, A. N., Christiaanse, B., et al. (2005). Psychische klachten en het gebruik van de geestelijke gezondheidszorg na de vuurwerkramp Enschede: Een longitudinale vergelijkende studie [Psychological problems and the use of mental 
health services after the fireworks disaster Enschede: A longitudinal comparative study]. Tijdschrift voor Psychiatrie, 47, 571582.

Van der Velden, P. G., Grievink, L., Kleber, R. J., Drogendijk, A. N., Roskam, A. J. R., Marcelissen, F. G. H., et al. (2006). Post-disaster mental health problems and the utilization of mental health services: A four-year longitudinal comparative study.
Administration and Policy in Mental Health and Mental Health Services Research, 33, 279-288.

Van Kamp, I., Van der Velden, P. G., Stellato, R., Roorda, J., Van Loon, J., Kleber, R. J., et al. (2006). Physical and mental health shortly after a disaster: First results from the Enschede fireworks disaster study. European Journal of Public Health, 16, 252-258. 